\title{
Los temporales de 1982 y la crisis económica, política y social de la dictadura en Chile
}

\author{
The storms of 1982 and the economic, political, and social crisis \\ of Chile's dictatorship
}

\author{
Pablo Camus Gayán* \\ Fabián Jaksic Andrade**
}

\begin{abstract}
RESUMEN
Los vínculos entre fenómenos meteorológicos severos y las crisis políticas, sociales y económicas, suscitadas en el devenir histórico, no han sido precisamente el foco de atención en la historiografía nacional. El objetivo de este estudio se concentra en analizar los efectos económicos, políticos y sociales del fenómeno El Niño 1982-1983 en un contexto de dictadura, con especial atención en los problemas de movilización social poblacional y de políticas de vivienda. Las fuentes primarias estudiadas fueron publicaciones periódicas nacionales, tales como diarios y revistas, además de la revisión de bibliografía especializada. Se propone que, en un contexto de recesión económica e inundaciones, y ante la ausencia del Estado, la organización de ollas comunes se configuró como la principal herramienta para enfrentar la crisis socioecológica desencadenada por los temporales, incentivando la creación de lazos de solidaridad entre vecinos y opositores que menoscabarían la autoridad del régimen militar. Al mismo tiempo, las inundaciones legitimaron la política de
\end{abstract}

Palabras clave: Inundaciones de 1982, fenómeno El Niño 1982-1983, ollas comunes, crisis.

\footnotetext{
* Chileno. Doctor en Historia, Pontificia Universidad Católica de Chile, Chile. Profesor del Instituto de Historia, Pontificia Universidad Católica de Chile. E-mail: pcamusg@ uc.cl

** Chileno. Doctor en Zoología, Universidad de California-Berkeley, Estados Unidos de América. Profesor del Departamento de Ecología, Pontificia Universidad Católica de Chile.E-mail: fjaksic@bio.puc.cl

Agradecemos al Proyecto FONDECYT N 1180537 “ ¿Despotismo hidráulico? Irrigación, organización social y conflictos por el agua en una sociedad en transición al capitalismo. Valle Central de Chile. 1856-1914", y al Center of Applied Ecology and Sustaintability (CAPES), Pontificia Universidad Católica de Chile, ANID PIA/BASAL FB0002.
} 
erradicaciones, una de las más grandes operaciones urbanas en la historia de Santiago de Chile.

\begin{abstract}
The links between severe meteorological phenomena and the political, social, and economic crises that have arisen in history have not exactly been the focus of attention in national historiography. This study aims to analyze the economic, political and social effects of the 1982-1983 El Niño phenomenon in a context of dictatorship, with particular attention to the problems of social mobilization of the population and housing policies. The primary sources studied were national periodicals, such as newspapers and magazines, and the review of specialized bibliography. We propose that in a context of economic recession and floods and an absent State, the organization of ordinary pots was configured as the primary tool to face the socio-ecological crisis triggered by storms. The latter encouraged the creation of solidarity ties between neighbors and opponents that would undermine the authority of the military regime. At the same time, the floods legitimized the eradication policy, one of the most extensive urban operations in the history of Santiago de Chile.
\end{abstract} Keywords: 1982 floods, 19821983 El Niño phenomenon, ordinary pots, crisis. 
Los impactos y transformaciones económicas, políticas y sociales derivados de eventos climáticos extremos, tales como temporales, inundaciones y sequías, parecen poner en cuestión la idea de la naturaleza como un telón de fondo atemporal y silencioso, pasivo y reiterativo en el que se desenvuelve la historia de la humanidad.

Uno de los fenómenos climáticos extremos, de impacto a escala planetaria, es el fenómeno El Niño. Desde tiempos inmemoriales fueron los pescadores de la costa sudamericana del Océano Pacífico quienes advirtieron un inusual calentamiento de las aguas del mar, alteración que se repetía con cierta frecuencia hacia fin de año, en plena época navideña. Esta coincidencia determinó que, en Perú, hace más de doscientos años, se bautizara este evento natural con un nombre que alude al nacimiento del "Niño Dios" (Bitrán, 1998: 3).

En las primeras décadas del siglo XX los científicos lograron identificar con mayor precisión este evento meteorológico recurrente, más o menos predecible que, de acuerdo con su magnitud, podía originar cambios climáticos de consideración, desencadenando grandes calamidades en distintos lugares del planeta. Se trataba de un fenómeno natural asociado con importantes perturbaciones en los regímenes de lluvias en los trópicos, cuyos resultados continentales eran sequías en áreas donde habitualmente llovía y precipitaciones torrenciales en zonas usualmente desérticas. En el hemisferio norte de América, por ejemplo, producía severas precipitaciones en el sureste de Estados Unidos, norte de México, golfo de México, estrecho de Florida y occidente de Cuba. Asimismo, se ha vinculado con sequías no solo en algunas partes de América del Sur, tales como el noroeste de Brasil, sino también en el sudeste de África, en el sur de Asia, en Indonesia y en Australia (Hernández, 2002).

Fue el evento de 1957-1958 el que puso a este fenómeno bajo la atención del mundo científico (Caviedes, 1997). Este calentamiento recurrente del Océano Pacífico ahora es ampliamente conocido por sus efectos catastróficos: lluvias torrenciales, inundaciones de ríos y deslizamientos de tierra que destruyen propiedades y cobran vidas en algunas regiones del mundo, al mismo tiempo que desencadenan graves sequías e incendios forestales en otras áreas. Las temperaturas cálidas del océano acaban con grandes poblaciones de peces y corales en aguas tropicales, y provocan migraciones a gran escala de vida marina. 
Tormentas furiosas, engendradas sobre las aguas calientes, erosionan las playas y destruyen las propiedades costeras, y en el pasado causaron numerosos naufragios (Caviedes, 2001: 304).

Por su relevancia a escala planetaria, El Niño ha llamado también la atención de algunos historiadores, quienes se han preguntado acerca de la influencia de este fenómeno climático en el devenir de los acontecimientos políticos, sociales y económicos. César Caviedes (2001), por ejemplo, proporciona observaciones planteando la influencia de El Niño en la conquista de los Incas, y en la derrota de Napoleón y de Hitler. Brian Fagan (2010), del mismo modo, analiza los efectos sociales y económicos de esta anomalía, a partir de los ejemplos del derrumbe del viejo reino en Egipto Antiguo, la sociedad Moche en Perú y de las tierras bajas de América Central.

El fenómeno El Niño ha dejado en el tiempo importantes conmociones en la costa americana del Océano Pacífico Sur, originadas por grandes temporales e inundaciones en las tierras bajas, y sequías extremas en los sectores más altos de la región andina. El Niño es conocido desde que civilizaciones preincas, como los Lima y los Nazca, se asentaron en las costas del Perú antiguo (Beresford-Jones, 2014). En el caso de Chile, se asocia a períodos de intensas precipitaciones (Jaksic, 1998).

\section{El fenómeno El Niño de 1982-1983: breve recuento de sus impactos a nivel global}

El fenómeno El Niño de 1982-1983 fue el primero en recibir una amplia difusión en los medios de comunicación de masas. Informes y reportajes en revistas como Reader's Digest y National Geographic comenzaron a referirse a "El Niño" como un fenómeno climático de alcance planetario, que se producía por el calentamiento de la superficie de las aguas del Océano Pacifico Oriental, lo cual afectaba directamente las condiciones atmosféricas globales, provocando graves inundaciones 0 sequías en los distintos continentes (Grove y Adamson, 2018). La Organización de las Naciones Unidas para la Agricultura y la Alimentación (1997) estimó que El Niño de 1982-1983 causó pérdidas por más de diez mil millones de dólares.

Al otro lado del Océano Pacífico, durante 1982 y 1983, una extraordinaria sequía afectó a Australia, Indonesia y Filipinas, siendo ésta una 
de las peores registradas en Australia desde que llegaron los europeos en 1789. La sequía originó tormentas de polvo e incendios de matorrales generalizados, al mismo tiempo que ocasionó cuantiosas pérdidas agrícolas y ganaderas. En Indonesia el fuego consumió 3,5 millones de hectáreas de bosque. En Nueva Guinea, heladas severas por encima de los dos mil doscientos metros de altura dañaron significativamente los cultivos básicos de batata, menoscabando la alimentación y economía de sus habitantes. También se produjeron incendios forestales con una frecuencia inusual en Côte d'Ivoire y Ghana, al oeste de África. Además, se registraron sequías en el sur de la India y en Sri Lanka. Etiopía, por su parte, experimentó una grave sequía, que fue utilizada en su favor por la dictadura etíope, originando una guerra civil y una gran hambruna, particularmente fuerte entre 1984 y 1985 (Grove y Adamson, 2018).

En tanto, El Niño de 1982-1983 provocó en Perú y Ecuador las intensas lluvias de 1983, que debilitaron los suelos fluviales provocando deslizamientos de tierra, destruyendo edificios e impidiendo el acceso al agua potable debido a los daños en las tuberías. El desborde del río Chimbote, a fines de marzo y principios de abril, afectó a aproximadamente treinta mil personas y destruyó el $85 \%$ de los hogares de los habitantes más pobres. Durante las lluvias de abril y mayo, casi la mitad de los hogares de Túcume fueron destruidos. Por su parte, la sierra andina peruana experimentó una sequía severa. La producción agrícola se redujo en dos tercios y se informó de una alta mortalidad de ganado y de llamas. Más aún, según Grove y Adamson (2018), en la hambruna resultante hubo informes de familias campesinas que vendían a sus hijos, un fenómeno generalmente asociado con las hambrunas del siglo XIX y antes, en lugar de finales del XX.

En Ecuador, las lluvias de marzo y principios de abril de 1983 destruyeron numerosas estructuras en la ciudad costera de Machala. La fuerte sedimentación del río Chira hizo que el agua retrocediera destruyendo las viviendas de los campesinos río arriba. El puente de Ñacara fue destruido por el desborde del río. La carretera Panamericana también fue arrasada a mediados de abril. Asimismo, los daños a los sistemas de alcantarillado causaron varias epidemias y enfermedades, en particular gastroenteritis y fiebre tifoidea. La mala alimentación también favoreció la propagación de la tuberculosis (Grove y Adamson, 2018; Caviedes, 1984). 
En Chile, el fenómeno El Niño se expresó con especial energía durante los días 25 al 28 de junio de 1982, cuando precipitaron 123,6 milímetros de agua en solo 96 horas, lo cual provocó la salida de ríos, esteros y canales en la Zona Central del país, afectando su infraestructura, equipamiento y vivienda. El sistema frontal afectó especialmente entre las regiones de Coquimbo y el Maule (Urrutia y Lanza, 1993). El tránsito vehicular fue interrumpido en diversos puntos, hubo cortes en las redes de energía, agua y telefonía. En Santiago se desbordó el río Mapocho, el canal San Carlos, el zanjón de la Aguada, además de otros cursos de agua, como los canales San Ramón, Las Perdices, El Carmen y El Canelo. Diversas poblaciones y campamentos, así como los asentamientos situados junto a los canales de regadío y los ríos, fueron arrasados por las aguas. El gobierno militar instaló un centro de refugio en el Estadio Nacional y organizó el "tren de la solidaridad", que viajó desde Puerto Montt a Santiago pidiendo ayuda para los damnificados. La Oficina Nacional de Emergencias (ONEMI) estimó que los temporales de junio de 1982 dejaron un saldo de 10.137 albergados, 15.272 damnificados, 800 heridos, 15 muertos, 2.605 viviendas dañadas, 965 destruidas, 15 caminos interrumpidos y 13 puentes con daños ( $L a$ Tercera, 4-VII-2020). Se registraron, además, "pérdidas millonarias en la agricultura de la zona central" (Solidaridad, 1982: 2).

Planteamos que, ante a la magnitud de la catástrofe, pobladores de los campamentos debieron organizarse en torno a ollas comunes para asegurar la alimentación de sus familias y vecinos. Estas organizaciones fueron el germen del reencuentro social y político de los pobladores, tras el largo "temporal" iniciado con el golpe militar de 1973. Así, ante un Estado ausente, las inundaciones de 1982 se transformaron en el inicio del fin de la dictadura militar. No quedaba más que organizarse desde dentro para sobrevivir a la crisis socioecológica y económica. Como lo señaló un clarividente titular de Las Últimas Noticias (27-VI-1982 citado en Vásquez, 2019: 38), "el temporal resultó peor que la recesión". El 18 de agosto de 1982 se organizó la primera "marcha del hambre" y, en adelante, las jornadas de protestas y el movimiento opositor al régimen militar incrementaron su intensidad. En los primeros años tras la crisis económica y ecológica, el protagonismo que tomaron los pobladores organizados fue fundamental para sostener el asedio vivido por la dictadura. Luego, mucha agua pasó bajo el puente, 
pero, a fin de cuentas, seis años después Augusto Pinochet era derrotado en las urnas.

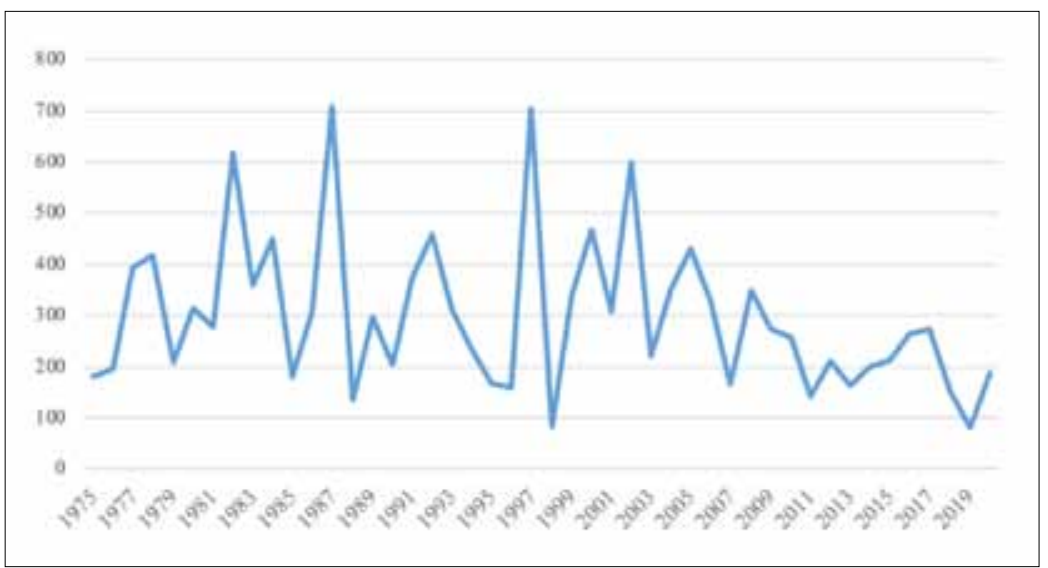

Figura $N^{\circ} 1$. Precipitaciones en Santiago de Chile, 1975-2020 (milímetros)

Fuente: Sociedad Nacional de Agricultura (Chile), Anuario Estadístico de la República de Chile, Dirección Meteorológica de Chile.

\section{Giro neoliberal, restructuración productiva e impactos sociales y económicos}

El almirante José Toribio Merino comentaba que el proyecto económico condensado en un documento conocido como "El Ladrillo", fue el "resultado de largos estudios realizados por un grupo de economistas de alto nivel académico, cuyo objetivo fue definir un conjunto de políticas coherentes e interrelacionadas que permitieran resolver la aguda crisis económica que vivía Chile y proponer los elementos básicos de una política económica global que hiciera posible un acelerado desarrollo". Los altos mandos de las otras ramas de las Fuerzas Armadas "tuvieron conocimiento de él solamente el día 12 de septiembre y, felizmente, lo acogieron con fe y gran sentido patriótico" (Merino, 1998: 397).

No obstante, al interior del gobierno hubo diferentes corrientes y disputas respecto del modelo económico a implementar. Hubo posiciones nacionalistas e incluso corporativistas que disputaron la supremacía a las concepciones más liberales y monetaristas. Fue necesario convencer a los militares, especialmente a Pinochet, puesto que 
la mayor parte de la oficialidad era cercana al tradicional desarrollismo estatal. Finalmente, tras un par de años de disputas, los economistas de "El Ladrillo" entraron al gobierno. El agravamiento de la inestabilidad monetaria habría facilitado la aceptación del discurso de los economistas neoliberales, partidarios de una drástica reducción del gasto público y del rol del Estado en la economía (Gárate, 2012).

Como es sabido, quienes estaban detrás del proyecto neoliberal era un grupo de economistas de la Universidad Católica de Chile, que habían sido becados desde la década de 1950 para estudiar economía en la Universidad de Chicago, donde enseñaba el máximo exponente del neoliberalismo, Milton Friedman. Éste, además, visitó Chile y se reunió con Augusto Pinochet el 21 de abril de 1975 (Rosende, 2007; Valdés, 2020). Una vez afianzados en el poder y con el respaldo del dictador, los denominados "Chicago Boys" aplicaron en el país una política económica caracterizada por la apertura al comercio internacional, la privatización de empresas estatales, la reducción drástica del gasto público y del déficit fiscal, la fijación de un tipo de cambio nominal, la liberalización financiera, la eliminación de obstáculos para la libre empresa y la desregulación de las relaciones laborales.

Después de un duro shock de ajuste estructural, con altas tasas de desempleo, hacia 1977 la economía mostraba ciertos signos de recuperación respecto de la aguda crisis experimentada. En 1979 se anunciaron las siete modernizaciones que afectaron ámbitos claves como la política laboral, seguridad social, salud y educación. Asimismo, se eliminaron todas las restricciones y controles en las operaciones de intermediación financiera internacional realizadas por la banca nacional (Bravo, 2012). La importación masiva de petrodólares, que los bancos nacionales prestaron al por mayor con el objeto de adquirir bienes de consumo, trajo una sensación de bienestar económico e incluso de euforia. En medio del boom económico los préstamos externos a los bancos nacionales se triplicaron en 1980. Los más optimistas hablaban del "milagro chileno".

No obstante, hacia mediados del año siguiente, y tras la estrepitosa quiebra del consorcio de empresas vinculadas a la Compañía de Refinería de Azúcar de Viña del Mar (CRAV), quedaron en evidencia las flaquezas del modelo económico, resintiéndose considerablemente la confianza nacional e internacional, sobre todo de la banca extranjera 
que el modelo necesitaba imperiosamente (APSI, 1981). La contenida crisis del sistema financiero se hizo evidente en el último trimestre de 1981. Para entonces, se sabía que $46 \%$ del capital de los bancos y las financieras estaba comprometido en carteras riesgosas. Las cesaciones de pagos se multiplicaban e iban produciendo un "efecto dominó" sobre el mercado de capitales (Cavallo et al., 2020). Precisamente, el desencadenante de la denominada "década perdida" latinoamericana fue la interrupción de los flujos de capitales hacia 1982. El sobreendeudamiento, la recesión mundial, los shocks del petróleo y el aumento de las tasas de interés convergieron para desencadenar una "tormenta perfecta", conocida como "la crisis de la deuda", que afectó a la economía mundial y a Chile en particular, y que llevó a todas las economías de la región a una profunda y prolongada crisis.

La fijación del dólar en 39 pesos era una medida tendiente a controlar la inflación, pero que, al mismo tiempo, permitía a los bancos pagar los intereses que cobraba el capital extranjero por sus préstamos. No obstante, la fijación del tipo de cambio y la apertura arancelaria indiscriminada presionaban contra una estructura industrial muy debilitada, haciéndola llegar a una situación de crisis tal que era inminente una quiebra generalizada (Análisis, 1982). A ello se sumaba la situación económica internacional que interrumpió los flujos de capitales de los bancos a los empresarios. Entonces, tras una debatida y tensa polémica, en la cual también se consideró una baja en los salarios (Solidaridad, $1^{\mathrm{a}}$ quincena de junio 1982), y luego de innumerables desmentidos sobre una posible depreciación, el 14 de junio de 1982 el gobierno militar anunció la devaluación del peso en un $18 \%$.

La medida hizo crecer de inmediato la deuda externa de manera exponencial. En el vendaval cayeron los principales grupos económicos y el Estado debió intervenir la banca. La medida benefició a los productores nacionales, pero hizo a la vez más atractiva la llegada de recursos extranjeros, tanto al sector primario exportador como también a aquellos que estaban en el mundo de la liquidación de bancos, industrias y tierras, ofertadas un $18 \%$ más barato que antes, incrementándose así el proceso de transnacionalización económica impulsada por el modelo neoliberal (Análisis, 1982).

Por otra parte, la reestructuración productiva, basada en la apertura externa, en la teoría de las ventajas comparativas, en el desman- 
telamiento del Estado, la desindustrialización y la concentración del capital, tuvo un significativo costo social, evidenciado en los elevados índices de cesantía, en el incremento de los allegados y de los campamentos, y en el alza en el costo de la vida. Entre marzo de 1982 y marzo de 1983 el pan subió $47,2 \%$, y el pasaje de microbús 59,7\%. Complementando al PEM (Programa de Empleo Mínimo) y dadas las altas tasas de cesantía, a partir de octubre de 1982 se inició la aplicación del Programa Ocupacional para Jefes de Hogar (POJH) (Ruz-Tagle y Urmeneta, 1984).

De acuerdo con Mariana Schkolnik y Berta Teitelboim (1988), investigadoras del Programa de Economía del Trabajo de la Academia de Humanismo Cristiano, en Chile, tras la implementación del modelo neoliberal, se manifestaban fenómenos sociales que no se conocían en el país hasta entonces, tales como

"la extraordinaria expansión de la mendicidad, el recrudecimiento y mayor ferocidad de los robos, la masificación de los vendedores de baratijas, cuidadores y limpiadores de autos, recolectores de botellas, fierros y basuras y, en general, los grandes contingentes de personas, hombres y mujeres, que en plena edad de desempeñar un trabajo productivo pululan en torno a cualquier ocupación, incluso momentánea, por conseguir un sustento para el día" (14).

Al quedar la dinámica socioeconómica librada a las fuerzas del mercado, las desigualdades en las relaciones capital-trabajo tendieron a agudizarse, pues, además, se restringieron los derechos y mecanismos de negociación laboral. La persecución de los dirigentes y la proscripción de las organizaciones sociales y políticas, la dura represión ejercida, el debilitamiento y desarticulación del movimiento sindical intentaron minimizar el poder y la influencia de los trabajadores y sus organizaciones en el desarrollo de los acontecimientos políticos y económicos nacionales.

Para los trabajadores y pobladores ya precarizados por la implantación del modelo económico, la devaluación del peso significó una nueva alza en el valor de algunos productos básicos, especialmente los primeros días tras el pánico que había provocado la medida. Así, "las alzas de precios de algunos productos comenzaron a caer como goterones sobre el frío invierno de Santiago a dos días de la decisión del gobierno de subir el precio del dólar de 39 a 46 pesos (...) la para- 
fina, la bencina, el azúcar y el aceite aparecieron con nuevos precios, todos productos de primera necesidad" (Solidaridad, $2^{\text {a }}$ quincena de junio 1982: 10). A este contexto económico y social se sumaba, en los primeros meses de 1982, el asesinato del principal líder sindical del momento, Tucapel Jiménez, y la muerte hasta ahora no aclarada del expresidente Eduardo Frei Montalva, ambos referentes y líderes de la oposición al régimen militar, lo cual, presumimos, hacía más presente la dura represión ejercida por la dictadura. En estas circunstancias ocurrieron los temporales e inundaciones de junio de 1982.

\section{Las inundaciones de 1982: ollas comunes, organización popular y jornadas de protesta}

Dos semanas después de la catástrofe financiera, sobrevino un nuevo desastre ahora atribuible a la naturaleza: el fenómeno El Niño. En un invierno lluvioso y luego de tres largos días de precipitaciones ininterrumpidas, el domingo 27 de junio de 1982, pasadas las 16:00 horas, el río Mapocho desbordó su cauce, dejando a miles de santiaguinos damnificados, con sus viviendas destruidas, bajo el barro o anegadas. En las comunas de Las Condes, Vitacura y Providencia se cayeron puentes e inundaron viviendas de sectores acomodados cercanos al Puente Nuevo de Lo Curro (que se derrumbó), así como también en La Pirámide y la Rotonda Pérez Zújovic. Pese a la moderna infraestructura existente, los colectores de aguas lluvias no pudieron absorber los torrentes que descendieron por las avenidas Las Condes, Kennedy, Andrés Bello y Vitacura, convirtiendo a la avenida Providencia en un verdadero río (Las Últimas Noticias, 28-VI-1982, citado en Vásquez, 2019: 38). Las poblaciones de El Esfuerzo y El Ejemplo fueron arrasadas por el desborde del caudal del río Mapocho, donde dos mujeres fallecieron debido a la fuerza del agua que las arrastró al pasar por el sector en que se hallaban (El Mercurio, 28-VI-1982, citado en Vásquez, 2019: 38).

Las inclemencias del temporal golpearon con mayor severidad a las precarias poblaciones y campamentos situados cerca de los cursos de agua de la ciudad, que se vieron sobrepasados por los violentos temporales y las avenidas de las aguas. Hubo problemas en Maipú, Pudahuel, Puente Alto, La Florida y otras comunas de la capital. De acuerdo con Solidaridad (1 $1^{a}$ quincena de julio 1982: 4), "Cientos de viviendas fueron barridas por los torrentes del río Mapocho (campamentos 28 de 
agosto y Tania), del Canal San Carlos (sectores 1 y 2, y campamentos del sector 3 de Lo Hermida), del Canal El Carmen (Villa El Rodeo y Campamento Gabriela Mistral) en el sector norte de la capital, y por las aguas de la quebrada de Macul, que borró del mapa el campamento 'Caballeros de la Montaña"' (Solidaridad, $1^{\text {a }}$ quincena de julio 1982: 4).

En Lo Hermida, los pobladores quedaron aislados y, en una acción espontánea, los hombres con las manos enlazadas formaron “una cadena humana que desafió al aluvión en plena noche, gesto que salvó vidas" (Colectivo de trabajadoras sociales, 1982: 128). De las cuarenta mil personas damnificadas fueron evacuadas mil quinientas y el resto "se quedó en el barro bajo la lluvia y con pánico de vivir otra experiencia de este tipo" (Colectivo de trabajadoras sociales, 1982: 128). No obstante, agobiado por la crisis económica, agudizada por la reciente devaluación del peso y la catástrofe financiera, el gobierno militar consideró que había otras prioridades que debía atender y que nada podía hacer "frente a un fenómeno natural imprevisible e incontrolable" (APSI, 1982).

Inicialmente, luego de la catástrofe, en las poblaciones cundió el desaliento y la desesperanza. No obstante, producto de la adversidad, la falta de recursos y del hambre que comenzaba a acosar conforme pasaban las horas, inmediatamente se incrementaron las redes de ayuda y emergieron diversas organizaciones sociales en torno a la alimentación en las poblaciones, las que permanecieron en el tiempo. Un estudio realizado por Clarisa Hardy (1986) identificó 39 ollas comunes solo en Peñalolén, La Florida y Puente Alto. En Lo Hermida, por ejemplo, en medio de la precariedad, pero "especialmente durante 1982, con la salida del canal San Carlos, surgieron las ollas comunes, grupos de salud, de comprando juntos, etc." (Schkolnik y Teitelboim, 1988: 14).

Conforme al testimonio de un colectivo de asistentes sociales que estuvo en las poblaciones en esos momentos, en una reunión de emergencia, al día siguiente del desborde del canal San Carlos y con la asistencia de algunos dirigentes y participantes de las comunidades cristianas, los pobladores comenzaron a organizarse y, en los días siguientes, surgió en Lo Hermida "la idea de encarar el momento más crítico en forma colectiva. Se pensó entonces en ollas comunes por manzana o sector. La idea propuesta contó con buena acogida. 
De una en una alcanzaron a ser 31 ollas, llegando a entregarse en un momento más de 6.000 raciones al día" (Colectivo de trabajadoras sociales, 1982: 129).

El desastre obligó a los pobladores a organizarse, ante la escasa ayuda e indiferencia del Estado frente a la emergencia. En agosto de 1982, en la población Lo Hermida había diez ollas comunes o bien -para simular y evitar la represión - "ollas familiares" u "ollas solidarias". De acuerdo con un reportaje de Hoy (1982), las ollas comunes en esta población "nacieron luego del temporal, pero persisten por la desocupación" (Hoy, 1982: 24). Los temporales y la crisis económica habían incidido negativamente en el empleo, que ya era escaso antes de la tragedia. La cesantía alcanzaba un $30 \%$, contando incluso a quienes estaban en los programas de ayuda del gobierno, como el PEM, la tasa más abultada de las últimas décadas en el país. Las encuestas realizadas por las comunidades cristianas de base mostraban que en la población Lo Hermida el desempleo alcanzaba el $60 \%$. La situación era crítica y desalentadora. Así, un poblador indicaba a los reporteros de la revista que "con el estómago vacío lo que queda es puro rencor. Dan ganas de salir a la calle y gritar la impotencia" (Hoy, 1982: 24).

Si bien inicialmente la prensa nacional situó su atención en lo sucedido en los barrios acomodados de la ciudad de Santiago, lo cierto es que los desbordes de los sistemas de canales de riego del valle causaron diversos perjuicios en las distintas comunas de Santiago. En este contexto, la Vicaría Pastoral Obrera indicaba que, en medio de la crisis económica y social que afectaba al país, había sobrevenido el temporal y las inundaciones, que habían arrasado con las poblaciones y originado más hambre, generalizando la organización de las ollas comunes. Había - señalaba la Vicaría - "una gran desesperanza y desmoralización en la gente", que estaba "destrozada porque creyó que aquí en Chile realmente se iba a producir un milagro y ahora ve que todas sus ilusiones han caído al suelo". En este contexto, la Iglesia Católica consideraba que en los últimos meses había aumentado la cesantía y también la delincuencia, los asaltos, los asesinatos, el alcoholismo, el uso de drogas y la violencia al interior de las familias. Y todo ello había sido "agravado por las inundaciones que causaron estragos en sectores densamente poblados" (Solidaridad, $1^{\text {a }}$ quincena de septiembre 1982: 10). 
Hasta el golpe militar del 11 de septiembre de 1973, las organizaciones de pobladores incluían una amplia gama de instancias, como juntas de vecinos, centros de madres, sociedades de adelanto, cooperativas de vivienda, centros juveniles, centros de rehabilitación de alcohólicos, centros de padres y otras de carácter más reivindicativo, como los "sin casa", las juntas de abastecimiento y precios (JAP), y las organizaciones de salud, justicia y vigilancia en los campamentos. Ese día comenzaron los allanamientos, las amenazas de bombardeo, el soplonaje, las acusaciones de arsenales, la detención arbitraria de dirigentes, el traslado a otras poblaciones, la designación de autoridades y líderes locales, y la apropiación de los locales comunitarios, todo lo cual derivó en la completa desarticulación del tejido social que los pobladores habían construido en las décadas previas (Valdés, 1986).

La organización social originada tras las inundaciones en torno a las ollas comunes y la prolongación de la crisis económica, rompieron las desconfianzas provocadas por la represión ejercida por los agentes de la dictadura y fortalecieron en el tiempo los lazos vecinales y locales, adquiriendo las organizaciones de base de pobladores otros caracteres y avanzando hacia niveles superiores de coordinación a nivel de población y de compromisos involucrados (Hardy, 1989). Surgieron de este modo organizaciones laborales-productivas, para el consumo básico, de servicios sociales, laborales, reivindicativas, de cesantes y de problemas habitacionales (Hardy, 1987).

El 11 de mayo de 1983 se llevó a cabo la primera jornada de protesta nacional con amplia participación de los sectores poblacionales, los cuales se transformaron en protagonistas de los hechos. Luis Moulian y Lydia Wolf (1990) destacan el carácter familiar de las protestas en general y en la población Herminda de la Victoria en particular, pues ocurrían alejados de la fábrica y cerca de los hogares, permitiendo la participación de los más pequeños. Al no concentrarse en los lugares de trabajo, sino en lugares de residencia, permitían al mismo tiempo transformar la jornada en un día distinto, en el que se desarrollaban "múltiples acciones de resistencia pasiva, como no hacer compras ese día, no enviar a los niños a la escuela, hacer fogatas para reunir a los grupos, 'cacerolear' y a partir de la segunda protesta, hacer barricadas" (53). 
A menos de un año de los temporales e inundaciones, y tras la recomposición de las redes sociales a partir de la organización de ollas comunes, las movilizaciones y jornadas de protesta contra el régimen crecieron exponencialmente, por lo que el gobierno del general Pinochet se vio obligado a ocupar militarmente la ciudad y declarar estado de sitio (Valdés, 1986). Como balance del año 1983, los muertos alcanzaron a 75 y los heridos a 156, destacándose el hecho de que el 50,1\% de los muertos fueron jóvenes entre quince y veinticinco años (Ramón, 2000: 258). Pese a la violenta represión ejercida por las autoridades, la organización de los pobladores no amainó, transformándose en un actor social fundamental en la desestabilización del régimen militar y en la eventual derrota de Augusto Pinochet y de la Junta Militar.

\section{Erradicaciones, segregación urbana, fragmentación social y crisis nacional}

Las inundaciones originadas por los temporales de junio de 1982 desnudaron y expusieron ante los medios de comunicación de masas, como la prensa y la televisión, la dura realidad de millones de chilenos afectados por la implementación de un modelo económico que tenía en la cesantía a un tercio de la población y que, además, había generado una situación en la cual miles de familias vivían de allegados o en campamentos precarios. De acuerdo con las cifras oficiales, se calculaba que el déficit habitacional alcanzaba a seiscientas mil viviendas y a dos millones de personas (Solidaridad, $2^{\mathrm{a}}$ quincena de julio 1982: 4).

Si bien las erradicaciones y la segmentación urbana han sido parte fundamental del desarrollo histórico de la ciudad, las inundaciones de 1982 contribuyeron decisivamente para transformar a Santiago en una urbe definitivamente segregada. La catástrofe fue el pretexto perfecto para expulsar a los pobladores de los campamentos asentados en los barrios acomodados de Santiago. Los intereses económicos - en tanto suelo valioso quedaba libre - y la aversión a los pobres o aporofobia habrían encontrado en el desborde del río Mapocho un motivo para desplazar a los pobladores del sector oriente de la capital de Chile. Las poblaciones asentadas en los márgenes del río habían sido arrasadas por el agua y el barro, por lo que plantear el traslado de las más de 700 familias damnificadas, que se encontraban en albergues transitorios, a 
soluciones habitacionales definitivas e higienizadas parecía una solución lógica, eficiente y hasta humanitaria.

En este contexto, los pobladores fueron desplazados muchos kilómetros a comunas como San Ramón y La Pintana, donde había viviendas ya construidas destinadas a militares, las cuales fueron cedidas para dar rápido remedio al problema. Los sectores de Lo Curro y Puente Nuevo - donde estaban emplazados los campamentos- se transformaron en espacios de conectividad urbana, al construirse espaciosas calles, avenidas y rotondas. En tanto, los sectores ocupados por los campamentos El Esfuerzo y El Ejemplo, se transformaron en Casa Piedra y Parque Bicentenario, respectivamente, siendo el primero un complejo que otorga una valorización económica al barrio, y el segundo una valoración social, en tanto espacio de esparcimiento y recreación para los vecinos (Bunster, 2020).

De acuerdo con el trabajo de Magdalena Bunster (2020), el desborde del río Mapocho es visto por los erradicados como la cuestión precipitante que habría definido su traslado a la periferia. En los recuerdos de sus entrevistados, la voluntad de los pobladores estaba en permanecer cerca de sus lugares de trabajo, en el sector oriente de la ciudad. La insistencia de continuar en sus precarias moradas, pese al peligro inminente, y de no trasladar sus pertenencias a tiempo, evidencian que percibían que salir del hogar y dejarlo a merced del río y las autoridades significaba abandonarlo todo para siempre. Muchos fueron obligados a salir de sus viviendas: "sí, nos sacaron de ahí y lloviendo salimos, entumidas de frío". Otros se habían visto con el agua hasta el pecho antes de abandonar los hogares, "andaban militares ya sacando a la gente y uno como es porfiá y no quiere dejar sus cosas". Paulina y Paty, por ejemplo, eran dos hermanas de El Esfuerzo que fueron llevadas por el río, "vivían al ladito de nosotros". No quisieron abandonar sus pertenencias y se vieron arrastradas por el torrente. Su madre, en cambio, vivió para contarlo y fue trasladada al sector de El Castillo, en la comuna de La Pintana (Bunster, 2020).

Más allá del episodio del desborde del río Mapocho, frente a la catástrofe el gobierno militar aprovechó la oportunidad para anunciar que adelantaría la puesta en marcha de un programa de erradicaciones, que consistía en "la entrega de sitios de 120 metros cuadrados en las que se instalará una unidad sanitaria que comprende baño y coci- 
na" (Solidaridad, $1^{\text {a }}$ quincena julio de 1982). El Decreto Ley No 2.552 de febrero de 1979, denominado "Programa de viviendas básicas de erradicación de campamentos", radicó y erradicó dentro de la ciudad a 28.703 familias entre 1979 y 1985 . Asimismo, se había aprobado el Decreto con Fuerza de Ley No 3.260 del 9 de marzo de 1981, que permitió la formación de nuevas comunas destinadas a acoger a la población erradicada (BCN, s/f). Del total de las familias erradicadas, la gran mayoría fue desplazada a comunas periféricas prácticamente rurales, como Puente Alto, La Granja, La Pintana, San Bernardo, Renca y Pudahuel (Scherman, 1990).

Sin embargo, no bastaba con agua potable y alcantarillado en medio de la nada misma. La ausencia de planificación urbana y de servicios básicos, de equipamiento e infraestructura, y de trabajo en los sectores de llegada, deterioró la calidad de vida de los erradicados tanto a soluciones habitacionales como a sitios urbanizados. El proceso de erradicaciones y el desarraigo del entorno habitual y de los lugares de trabajo trajo como secuela la atomización, desarticulación y pérdida de inserción económica y comunitaria de los pobladores. Adicionalmente, significó la quiebra de las organizaciones de base, lo cual facilitó el control policial de los barrios populares (Ramón, 2000).

Así, la política de vivienda de aquellos años logró entregar efectivamente una solución a familias que vivían en condiciones paupérrimas, mejorando con ello su calidad de vida, al tener acceso a agua potable y baño al interior del hogar. No obstante, dicha medida abordó solo una parte del problema, al mismo tiempo que concentró la pobreza y generó las condiciones para su reproducción en la periferia sur y poniente de la ciudad de Santiago (Ducci, 1997). Del mismo modo, la reconfiguración territorial gestada durante el régimen militar comenzó a cristalizar problemas tales como la violencia territorial, narcotráfico, consumo de drogas y delincuencia, cuyos efectos psicosociales sobre los pobladores dan cuenta de la escasa vida comunitaria, el desinterés por los pares y el impacto negativo de las actividades delictivas en la vida de niños y adolescentes. (Melo y Yupanqui, 2016).

$\mathrm{Al}$ respecto, el visionario pronóstico realizado poco después de las inundaciones por la Comunidad Cristiana de Lo Barnechea, en relación con lo que terminaría por suceder socialmente con las erradicaciones, era esclarecedor: "no hay que erradicar a personas que han vi- 
vido toda una vida aquí. No debemos estar creando dos Santiago. Uno de los pobres y otro de los ricos, porque eso es avivar una confrontación de clases permanente" (Solidaridad, $2^{\text {a }}$ quincena julio 1982: 11).

En suma, la reorganización neoliberal del espacio de la ciudad de Santiago, justificada por las inundaciones, perjudicó irreversiblemente el potencial agrícola de su entorno rural, incrementó los costos públicos y privados de funcionamiento de la ciudad, y provocó deterioros en las condiciones urbanas de un numeroso contingente de familias de bajos recursos y capacidades de acción. El traslado de pobladores desde otras localidades permitió superar en parte sus penurias habitacionales y sanitarias, pero a costa de reducir sus niveles de integración espacial a la ciudad y de inclusión en un contexto social más heterogéneo, provisto de redes formales e informales de trabajo, de difusión de innovaciones y de mecanismos de convivencia y apoyo solidario, limitando drásticamente sus posibilidades ocupacionales y sus oportunidades de acceso a los bienes y servicios. El aislamiento y la unificación de la pobreza se fueron consolidando en un circuito negativo, debido al acrecentamiento de las distancias medidas en costos monetarios y tiempos de viaje, y sus consecuencias sobre el empleo y la certidumbre laboral, a la pérdida de la individualidad en la asociación involuntaria a un conjunto social discriminado por sus rasgos negativos y, finalmente, a la inseguridad en un medio donde se desarrollan procesos de descomposición institucional, violencia y degradación (Gurovich, 1999).

\section{Consideraciones finales}

A partir del análisis de las fuentes documentales asociadas al periodo de las inundaciones de 1982 en la Zona Central de Chile, ¿podemos considerar a la Naturaleza como un actor de los acontecimientos históricos? Es evidente que las inundaciones no fueron la causa de la caída de la dictadura militar, pero sí tal vez influyeron o, mejor dicho, fueron un componente o factor coadyuvante que marcaría el inicio del fin de la dictadura militar en Chile.

De acuerdo con los testimonios recogidos, en un contexto de aguda recesión económica y de alta cesantía, irrumpieron súbitamente el temporal y las inundaciones, obligando a los pobladores afectados a organizarse en ollas comunes que, al menos, aminoraran el hambre de los vecinos, niños y ancianos. Muchas poblaciones arrasadas por el agua y 
el lodo se organizaron en ollas comunes. Estas organizaciones fueron el germen de un nuevo encuentro entre vecinos que vivían desconfiados entre sí, tras la dura represión vivida desde el golpe militar de 1973. Las ollas comunes se transformaron en un punto de reencuentro. Tras ellas, comenzaron a gestarse múltiples instancias que permitieron la apertura de nuevas organizaciones y perspectivas políticas, económicas y sociales. Así, las ollas comunes obligaron al encuentro entre los pobladores, lo cual permitió, incentivó y fortaleció los lazos de solidaridad y las iniciativas colectivas que se expresaron, por ejemplo, en la "marcha del hambre" de agosto de 1982 y en las jornadas de protesta del año siguiente.

Asimismo, las inundaciones justificaron también una gigantesca operación urbana que trasladó la pobreza a las comunas periféricas de la zona surponiente de la ciudad. Frente al efecto en la opinión pública que produjo la desgracia y la pérdida de viviendas de los sectores más desposeídos, las inundaciones legitimaron la idea de erradicar a los pobladores e instalarlos principalmente en las comunas semi rurales de Puente Alto, La Pintana, San Bernardo, Lo Espejo, Maipú y Pudahuel. Ciertamente, esta operación urbana, hasta el día de hoy, ha tenido un alto costo social, al concentrar la reproducción de la pobreza enviando a los pobladores a espacios sin equipamiento, servicios e infraestructura, y mucho menos puestos de trabajo.

\section{Referencias bibliográficas}

\section{Fuentes primarias}

\section{a) Publicaciones periódicas}

Análisis, Santiago, 1982.

APSI, Santiago, 1981-1982.

Hoy, Santiago, 1982.

Solidaridad, Santiago, 1982.

\section{Fuentes secundarias}

\section{a) Artículos y capítulos de libros}

Bitrán, D. (1998). El fenómeno El Niño: su naturaleza y los riesgos asociados a su presencia recurrente. Documentos de proyectos e investigación. México: CEPAL. 
Bravo, V. (2012). “Neoliberalismo, protesta popular y transición en Chile 1973-1989", en Política y Cultura, ํㅜ 37, pp. 85-112.

Bunster, M. (2020). "Inundación y erradicación: El Mapocho se lleva la población, Santiago 1982 -2019", en Seminario Simon Collier 2020. Santiago: Instituto de Historia, Pontificia Universidad Católica de Chile.

Caviedes, C. (1984). "El Nino 1982-83", en Geographical Review, Vol. 74, $\mathrm{N}^{\circ}$ 3, pp. 267-290.

Caviedes, C. (1997). “Cincuenta años de uso y mal-uso de El Niño", en Espacio y Desarrollo, No 9, pp. 117-135.

Colectivo de trabajadoras sociales (1982). "Temporal, ollas y orden (registro para un archivo de emergencias), en Proposiciones, $\mathrm{N}^{\circ}$ 7, pp. 125-132.

Ducci, M. (1997). "Chile: el lado obscuro de una política de vivienda exitosa”, en EURE, Vol. 23, № 69, pp. 99-115.

Gurovich, A. (1999). "Una ciudad interminable: La Pintana", en Revista de Urbanismo, $\mathrm{N}^{\circ}$ 1, pp. 1-10.

Hernández, B. (2002). “El Niño-Oscilación del Sur (ENOS) y los frentes fríos que arriban a la región occidental cubana”, en Investigaciones marinas, Vol. 30, $\mathrm{N}^{\circ}$ 2, pp. 3-19.

Jaksic, F. (1998). "The multiple facets of El Niño/Southern Oscillation in Chile", en Revista Chilena de Historia Natural, Vol. 71, $\mathrm{N}^{\circ}$ 2, pp. 121-131.

Valdés, T. (1986). El movimiento poblacional: recomposición de las solidaridades sociales. Documento de Trabajo № 283. Santiago, Chile: FLACSO.

b) Libros

Beresford-Jones, D. (2014). Los bosques desaparecidos en la antigua Nasca. Estudio de un caso de colapso ecológico y cultural. Lima: Antares.

Caviedes, C. (2001). El Niño in History: Storming Through the Ages. Gainesville: University Press of Florida.

Fagan, B. (2010). La corriente del niño y el destino de las civilizaciones. Inundaciones, hambrunas y emperadores. Barcelona: GEDISA Editorial.

Gárate, M. (2012). La revolución capitalista de Chile. Santiago, Chile: Ediciones Universidad Alberto Hurtado. 
Grove R. y G. Adamson (2018). El Niño in World History. Palgrave Studies in World Environmental History.

Hardy, C. (1986). Hambre + dignidad = ollas comunes. Santiago, Chile: Academia de Humanismo Cristiano, Programa de Economía del Trabajo.

Hardy, C. (1987). Organizarse para vivir: pobreza urbana y organización popular Santiago, Chile: Academia de Humanismo Cristiano, Programa de Economía del Trabajo.

Hardy, C. (1989). La ciudad escindida. Santiago, Chile: Academia de Humanismo Cristiano, Programa de Economía del Trabajo.

Merino, J. (1998). Bitácora de un almirante. Memorias. Santiago, Chile: Editorial Andrés Bello.

Moulian, L. y L. Wolf (1990). Herminda de La Victoria. Aspectos Históricos. Santiago, Chile: Vicaría Zona Oeste.

Ramón, A. (2000). Santiago de Chile (1541-1991): historia de una sociedad urbana. Santiago, Chile: Ed. Sudamericana.

Rosende, F. (Editor) (2007). La Escuela de Chicago: Ensayos en honor a Arnold C. Harberger. Santiago, Chile: Ediciones Universidad Católica.

Ruiz-Tagle, J. y R. Urmeneta (1984). Los trabajadores del programa de empleo mínimo. Santiago, Chile: Academia de Humanismo Cristiano, Programa de Economía del Trabajo.

Scherman, J. (1990). Techo y abrigo: las organizaciones populares de vivienda: Chile, 1974-1988. Santiago, Chile: Academia de Humanismo Cristiano, Programa de Economía del Trabajo.

Schkolnik, M. y B. Teitelboim (1988). Pobreza y desempleo en las poblaciones. La otra cara del modelo neoliberal. Santiago, Chile: Academia de Humanismo Cristiano, Programa de Economía del Trabajo.

Urrutia, R. y C. Lanza (1993). Catástrofes en Chile, 1541-1992. Santiago, Chile: Editorial La Noria.

Valdés, J. (2020). Los economistas de Pinochet: la Escuela de Chicago en Chile. México: Fondo de Cultura Económica.

c) Sitios web

Cavallo, A. et al. Sitio web de Interferencia. Recuperado de https:// interferencia.cl/articulos/fines-de-1981-la-dictadura-interviene-cuatro-bancos-y-cuatro-financieras, revisado el 30XII-2020. 
Sitio web de la Biblioteca del Congreso Nacional de Chile. Recuperado de https://www.bcn.cl/leychile/navegar?i=3396, revisado el 30-XI-2020.

Sitio web de La Tercera. Recuperado de https://www.latercera.com/ que-pasa/noticia/las-torrenciales-lluvias-de-1982-el-ultimo-gran-desborde-del-mapocho-podria-volver-a-ocurrir/ WYY2KWUOCRAY7MKHSUVD3VL4D4/, revisado el 30-IX2020.

Sitio web de la Organización de las Naciones Unidas para la Agricultura y la Alimentación. Recuperado de http://www.fao.org/ NOTICIAS/1997/970904-s.htm, revisado el 18-X-2020.

d) Tesis

Vásquez, C. (2019). Ciudad, Naturaleza, Estado: una ecología política de Santiago en tres desastres socio naturales (1982-1997). Tesis para optar al grado de Magíster en Historia. Santiago, Chile: Pontificia Universidad Católica de Chile.

Melo, S. y M. Yupanqui (2016). Memorias y significados de los pobladores sobre las erradicaciones de sus campamentos durante la dictadura cívico-militar (1973-1990) asociados a efectos psicosociales. Tesina para optar al grado de Licenciado en Psicología. Santiago, Chile: Universidad Academia de Humanismo Cristiano. 